\title{
A COMUNICAÇÃO NÃO VIOLENTA NO MERCADO DE TRABALHO DA MULHER JORNALISTA
}

\author{
Nonviolent communication in the labor market of woman journalist
}

\section{Comunicación no violenta en el mercado de trabajo de la mujer periodista}

Louise Ariane da Campo Jornalista e estudante de mestrado em Texto, Discurso e Relações Sociais no Programa de Pós-Graduação em Letras da Universidade Federal de Pelotas. dacampolouise12@gmail.com

Geder Luis Parzianello Professor Associado da Universidade Federal do Pampa, doutor em comunicação com pósdoutorado em Estudos de Mídia pela Universität Paderborn, Alemanha. gederparzianello@yahoo.com.br

\section{Resumo}

O presente artigo pretende evidenciar, com base na Análise de Discurso (AD) de filiação francesa em Michel Pêcheux, os assédios e constrangimentos sutis sofridos por mulheres jornalistas no exercício da profissão no Rio Grande do Sul. Para isso, foram realizadas 13 entrevistas com jornalistas mulheres do Rio Grande do Sul utilizando-se da técnica de entrevista semiestruturada. Buscou-se identificar se o silenciamento diante desses assédios e constrangimentos geram marcas de uma forma de comunicação violenta conforme a concepção teórica de Marshall Rosenberg. Conceitos como os de gênero, identidade, comunicação não-violenta e análise de discurso ancoram este artigo.

Palavras-chave: Mulheres jornalistas. Violência. Comunicação não violenta.

\begin{abstract}
This article aims to show, based on the Discourse Analysis of French affiliation in Michel Pêcheux, the subtle harassments and constraints suffered by women journalists in the exercise of their profession in Rio Grande do Sul. For this, 13 interviews were conducted with female journalists from Rio Grande do Sul using the semi-structured interview technique. We sought to identify whether the silencing in the face of these harassments and constraints generates marks of a form of violent communication according to the theoretical conception of Marshall Rosenberg. Concepts such as gender, identity, nonviolent communication and discourse analysis anchor this article.
\end{abstract}

Key words: Women Journalist. Violence. Non violent communication.

\section{Resumen}

Este artículo pretende destacar, basado en el Análisis del Discurso de la afiliación francesa en Michel Pêcheux, los sutiles hostigamientos y limitaciones que sufren las mujeres periodistas en el ejercicio de su profesión en Rio Grande do Sul. Para eso, fueron realizadas 13 entrevistas con mujeres periodistas de Rio Grande do Sul utilizando la técnica de entrevista 
semiestructurada. Intentamos identificar si el silenciamiento ante estos hostigamientos y restricciones genera marcas de una forma de comunicación violenta de acuerdo con la concepción teórica de Marshall Rosenberg. Conceptos como género, identidad, comunicación no violenta y análisis del discurso anclan este artículo.

Palabras clave: Mujeres periodistas. Violencia. Comunicación no violenta.

\section{INTRODUÇÃO}

"Não sou 'uma mulher'. Sou uma jornalista" (BBC BRASIL, 2017), foi o que respondeu Ana Arruda Callado, primeira jornalista mulher a ocupar o cargo de chefia de reportagem de um jornal no Brasil, em 1966. A afirmação foi feita em resposta ao Coronel Lino Teixeira. Na ocasião, a jornalista pedia permissão para ser incluída à expedição da "Caravana de Integração Nacional”, que percorreria a Belém-Brasília pela primeira vez. O Coronel, de início, negou o pedido justificando que não havia hipótese de levar uma mulher a um local com mais de 300 homens. Após insistência da jornalista, o Coronel decidiu incluí-la à expedição.

A história dessa mulher não é apenas uma, mas, é o espelho retrovisor para uma realidade que é central nessa pesquisa. O que buscamos neste trabalho foi identificar os constrangimentos e assédios que as mulheres jornalistas sofrem durante o exercício da profissão.

Quando Ana Arruda Callado se torna chefe de reportagem do Diário Carioca, a novidade é uma polêmica. Historicamente, os homens lideraram as redações jornalísticas, tanto nacionais quanto internacionais. Apesar de lenta, no entanto, a mudança aconteceu. Dados do Ministério do Trabalho apontaram que em 1986 as mulheres jornalistas representavam 36\% dos profissionais do país. Já em 1996, a proporção era de quatro jornalistas mulheres para cada grupo de 10 profissionais (ROCHA, 2004).

Segundo o Perfil do Jornalista Brasileiro (2012), estudo realizado pela Universidade Federal de Santa Catarina (UFSC), 64\% dos profissionais jornalistas são mulheres. Mesmo representando a maior parcela de profissionais da imprensa, a mulher ainda assim não possui a mesma média salarial de seus colegas homens. O estudo apontou que as mulheres mais jovens ganhavam menos que os homens; eram maioria em todas as faixas de até cinco salários mínimos e minoria em todas as faixas superiores a cinco salários mínimos.

A presente pesquisa aborda os constrangimentos e assédios sofridos por mulheres jornalistas do Rio Grande do Sul. Além disso, aborda como o silenciamento de algumas mulheres jornalistas perante agressões sofridas pode gerar uma comunicação violenta. Nesse 
sentido, as informações que trazemos na introdução contextualizam a realidade em torno do problema e apontam na direção do que pretendemos investigar.

A escolha por pesquisar mulheres jornalistas justifica-se porque, apesar do avanço dos direitos das mulheres através das lutas femininas e da profissionalização da mulher no mercado de trabalho, ainda existe discriminação de gênero, desigualdade e constrangimentos sofridos pelas mulheres jornalistas no ambiente profissional. Estas discriminações ainda são sentidas em parte porque as mudanças culturais que determinam padrões são mesmo historicamente lentas e também porque são séculos de comportamentos arraigados no mundo patriarcal, social e do trabalho até que finalmente a mulher ingressou no mercado profissional, o que no Brasil foi se dando lentamente, a partir do final da década de 1970 apenas, menos de seis décadas do tempo em que vivemos.

Trabalhar a temática da mulher jornalista é relevante, pois, permite que outras consciências se construam e todos os sujeitos percebam situações que antes não eram suficientemente claras ou até mesmo ignoradas, como as situações de ataques sutis contra mulheres que podem afetar as suas vidas pessoais e profissionais.

Nesse sentido, a hipótese da pesquisa não se limita à ideia de que o machismo existe, posto que isso é um fato histórico. Conforme pesquisas já realizadas que confirmam que há a existência de um silenciamento a respeito das violências sofridas por mulheres jornalistas no ambiente de trabalho. A hipótese dessa pesquisa é de que ao silenciarem os constrangimentos e assédios sofridos, as mulheres geram uma comunicação violenta, contra si, porque sofrerão sozinhas e contra o agressor, pois sem o conflito o mesmo continuará a reproduzir esses ataques. Se as mulheres são vítimas das primeiras formas de violência, aquelas que as atingem via homens com os seus constrangimentos e agressões não só no trabalho, mas, especialmente nestes locais, elas acabam por praticarem uma segunda forma de violência, ainda mais simbólica e silenciosa, mas contra si mesmas, por não denunciarem nem reagirem ao agressor. Não são culpadas como no caso do homem que as agride. Mas é preciso entender que falamos aqui de duas violências diferentes e de formas distintas de culpabilidade. No segundo caso, sua culpa é relativa à medida que seu silêncio é causa de reforço do autossofrimento e não de um sofrimento a terceiros. Na verdade, nos dois casos ela é vítima. Ela é duplamente vítima. Mas sobre a primeira violência ela não tem nenhuma responsabilidade.

O objetivo geral da pesquisa é identificar comportamentos de assédio e constrangimentos contra mulheres jornalistas do Rio Grande do Sul no exercício da profissão 
e suas características. Nessa perspectiva, os objetivos específicos são: reunir depoimentos de mulheres jornalistas do Rio Grande do Sul em relação a agressões sutis sofridas ou conhecidas e identificar se o silenciamento de algumas mulheres perante os assédios e constrangimentos gera marcas de uma comunicação violenta.

O processo de desenvolvimento desta pesquisa se dá, primeiramente, através do método da pesquisa bibliográfica e documental, ela é a base de todo trabalho acadêmico. Para Stumpf (2005), a pesquisa bibliográfica se inicia antes mesmo da delimitação do problema que será investigado, já que haverá uma leitura preliminar a fim de identificar conceitos até se obter uma formulação objetiva e clara do objeto.

$\mathrm{Na}$ etapa de entrevistas, foi utilizada a técnica da entrevista semiestruturada. Esse tipo de entrevista é utilizada a fim de delimitar o volume das informações trazendo um maior direcionamento ao tema de interesse. Segundo Michel (2005), o entrevistado possui uma maior liberdade para desenvolver cada situação nesse tipo de entrevista, pois ele poderá explorar a questão de uma forma mais ampla. Nos meses de abril e maio de 2018 esta pesquisa começou a amadurecer, a partir disso iniciou-se o período de mapeamento das entrevistadas em potencial, após, entramos em contato com essas mulheres jornalistas em exercício no Rio Grande do Sul, através de redes sociais como Facebook, Instagram e Linkedin. Entre os meses de junho e julho de 2018 efetivaram-se as entrevistas presenciais. Para análise dos enunciados da entrevista utilizamos como base o dispositivo teórico-analítico da Análise de Discurso pêcheuxtiana.

\section{PRIMEIRO PERCURSO TEÓRICO}

Ao propor uma discussão sobre o papel e lugar da mulher no jornalismo é preciso pensar sobre gênero e identidade. Para Butler (2003), o gênero diz respeito à construção social e histórica do ser masculino e do ser feminino. Segundo a autora, sociedades diferentes atribuem certas características e atitudes para cada um deles.

O gênero, atualmente, é visto como uma "variável fluida" (GAUNTLETT, 2002), que está suscetível à mudança, de acordo com o tempo e contexto, não sendo mais um atributo e sim uma performance. Esta performance se refere a uma forma de estar, de se ver, de se mostrar aos outros e que pode se modificar constantemente.

Os gêneros, construídos culturalmente, servem em sociedade como pressuposto para atributos como "homens são mais agressivos, mulheres são mais emocionais", por exemplo. Pressupostos, que como aponta Veiga (2012), são tomados como parâmetros do normal para 
constituição de regras que vão reger o social, construindo uma hierarquia social excludente que pode ser entendida por meio da imagem de uma pirâmide de distribuição do poder. O topo dessa pirâmide é ocupado pelo masculino e a base pelo oposto: o feminino (RUBIN apud VEIGA, 2012).

Até meados do século XX, a representação dominante feminina era da 'mulher do lar' que tinha como responsabilidade 'cuidar da casa, do marido e dos filhos'. O espaço do lar era a referência maior, o lugar de onde as mulheres apenas saíam para fazer as compras, levar os filhos na escola ou para acompanhar seus maridos (FRIEDMAN, 1971). Esse lugar das mulheres era reservado ao privado. Além da preocupação com a casa, essa mulher também precisava estar sempre atenta a sua aparência, se atualizando dos conceitos de beleza, cuidando seu físico, certificando que não estivesse envelhecendo e tomando cuidado, principalmente, para não 'perder o controle' (WOLF, 1992, p.12).

Com o movimento feminista, isso se modifica, pois, todo o sistema (político, social, ideológico e filosófico) começa a mudar a partir das reivindicações das mulheres pelo direito à vida pública. Ou seja, a própria representação das identidades femininas começa a se transformar. A construção e a mudança da identidade acontecem no decorrer do desenvolvimento social e individual, pois à medida que a sociedade modifica comportamentos e pensamentos ela se desenvolve e, assim, a mulher vai tendo novas e sucessivas transformações. A evolução da compreensão sobre gênero não é a única modificação profunda que resulta da luta das identidades, sobre as quais repousam muitas outras disputas de sentido.

Conforme Hall (2000, p.109), as identidades são construídas dentro do discurso e não fora, “(...) nós precisamos compreendê-las como produzidas em locais históricos e institucionais específicos, no interior de formações e práticas discursivas específicas, por estratégias e iniciativas específicas. ", o autor também afirma que as identidades vão emergir no interior das relações de poder. Devido a isso, as identidades acabam sendo "produto da marcação da diferença", e não uma "unidade idêntica".

Essas construções de identidades, tanto feminina quanto masculina, se dão desde formações imaginárias que se estabelecem nos discursos os quais atestam um poder já estabelecido, por meio do qual os homens ocupam os cargos de maior relevância.

Com isso, a identidade feminina em diversas esferas sociais se apaga e é condicionada ao lugar privado. Esse processo de apagamento do sujeito expressa, sobretudo, uma relação de poder, de um indivíduo sobre o outro. Na visão de Foucault apud Gauntlett (2002), o poder 
não é algo que se pode ter, ao contrário, o poder é algo que é exercido dentro das interações. O poder flui através das relações.

Essa relação de poder e dominação entre os gêneros efetivada de forma sutil pode ser explicada através do conceito de "violência simbólica" de Pierre Bourdieu:

Também sempre vi na dominação masculina, e no modo como é imposta e vivenciada, o exemplo por excelência desta submissão paradoxal, resultante daquilo que eu chamo de violência simbólica, violência suave, insensível, invisível a suas próprias vítimas, que se exerce essencialmente pelas vias puramente simbólicas da comunicação e do conhecimento. (BOURDIEU, 2011, p.7)

Como o indivíduo está incluído em sociedade como homem ou mulher, Bourdieu (2011) diz que o mesmo incorpora, sob a forma de esquemas inconscientes de percepção e apreciação, as estruturas históricas da ordem masculina. A dominação masculina se evidencia através do que o autor chama de "máquina simbólica". Essa máquina se alicerça em diversas formas de dominação: na divisão social do trabalho (e também na divisão do trabalho social), que é bem estrita nas atividades atribuídas a cada um dos sexos; na estrutura do espaço e do lugar, onde ao homem cabe o lugar da assembleia ou de mercado, e quanto para a mulher é reservado o espaço da casa.

O poder e a dominação se materializam através do discurso. Se não há um discurso de poder, não há o poder. E nesse sentido, as relações de gênero são um campo primordial de “significar relações de poder" (SCOTT, 1988, p.42).

Segundo Stocker e Dalmaso (2018), para que determinado discurso possa ser feito em algum momento da história, é preciso que estejam dadas as condições para sua aparição, existência e circulação. Como reflete Foucault apud Stocker e Dalmaso (2018), as possibilidades desse discurso estão reguladas e regulamentadas por uma ordem do discurso, onde cada enunciado é compreendido como um bem que tem regras de aparecimento, condições de apropriação e de utilização. Nesse sentido, discursos machistas ainda são comuns na atualidade, pois estão dadas as condições necessárias para sua aparição, existência e circulação.

Para efeito dessa pesquisa, nos embasamos na Análise de Discurso (AD) de linha francesa por Michel Pêcheux (e Eni Orlandi, no Brasil), para refletir os efeitos de sentido produzidos pelo nosso corpus - os relatos das mulheres jornalistas. A Análise de Discurso é complexa, pois não é apenas uma teoria ou um referencial metodológico; ela é considerada como uma ciência de entremeio (ORLANDI, 2006). A principal justificativa para nos embasarmos na Análise de Discurso, nesse estudo, é por que, como aponta Orlandi (2010), ela 
é capaz de nos colocar em estado de reflexão, mas sem cair na ilusão de que somos conscientes de tudo que existe. Ela nos permite sermos capazes de uma relação menos ingênua com a linguagem. O discurso, para a autora, é a palavra em movimento, uma prática de linguagem, ou seja, observa-se o indivíduo falando. Com a AD busca-se entender a língua enquanto sentido, como trabalho simbólico e como parte do trabalho social.

Para Pêcheux (1997), o discurso é sempre pronunciado a partir de condições de produção dadas, esse processo de produção do discurso é definido como "conjunto de mecanismos formais que produzem um discurso de tipo dado em 'circunstâncias' dadas" (PÊCHEUX, 1997, p.74), o que ele apresenta como 'circunstâncias' de um discurso são as suas condições de produção. Nesse sentido, o que as entrevistadas relatam em suas entrevistas parte de condições de produção dadas e é preciso refletir sobre elas, como faremos a seguir.

Quando o indivíduo nasce, portanto, ele já está em um meio onde há discursos formados e assim é que ele ouve e reproduz discursos machistas, através de seus enunciados e ações. A cultura rio-grandense é fortemente marcada pela figura do gaúcho homem que parece estar em uma posição de poder e força maior que a da mulher. Em criações artísticas e literárias como contos, poesias e músicas que trabalham com a temática do tradicionalismo gaúcho, a mulher é representada, diversas vezes, como subordinada ao homem mesmo no ambiente de seu tradicional domínio, por exemplo, a cozinha da casa colonial, pois o homem é quem decide o que comer e quando tem fome e à mulher cabe servi-lo. Ainda que responsável pelo lar, historicamente, por muitos séculos, a mulher esteve apoiada na figura do patriarca, não teve direito à opinião e fez dela submissa. Ainda hoje, pessoas seguem esse modelo de representação e reproduzem esses discursos construídos socialmente.

Nesse sentido, Orlandi (2010) aponta que o trabalho simbólico do discurso se dá na base da produção da existência humana. A Análise de Discurso entende a linguagem como mediação necessária entre o indivíduo e a realidade natural e social. Essa mediação, que é o discurso, permite tanto a permanência e a continuidade quanto o deslocamento e a transformação do indivíduo e da realidade em que ele está inserido.

Os discursos são como dinâmicas sociais e como uma forma de prática comunicacional. Ou seja, toda comunicação é discursiva e as pessoas se comunicam através do discurso. Esses discursos estão tencionados por sujeitos que têm interesses e ideologias. Em um estudo da década de 60 do psicólogo e pesquisador estadunidense, Marshall Rosenberg, que descreve o quanto é decisivo, numa prática comunicacional, conhecer e 
perceber o sentimento do outro. Esse espaço de escuta nessa teoria desenvolvida por Rosenberg é chamado de "Comunicação não-violenta" (CNV).

Para nosso trabalho, a CNV é utilizada com o objetivo de entender como o silenciamento de algumas mulheres perante as violências sofridas pode gerar uma Comunicação Violenta. Em 2017, uma pesquisa realizada pelo Gênero e Número e pela Abraji (Associação Brasileira de Jornalismo Investigativo) com mais de 500 jornalistas brasileiras mostrou que o machismo afeta as profissionais em seu ambiente de trabalho. Os resultados apontaram que a presença de atitudes sexistas estava presente em redações de todo o país, em diversas situações, como: assédio sexual, discriminação, humilhação e desigualdade.

O estudo também apontou que apenas $15,1 \%$ das entrevistadas denunciaram à empresa a situação de assédio ou machismo sofrida no ambiente de trabalho. Esse silenciamento pode ser entendido como uma Comunicação Violenta, à medida que, o mesmo afeta e machuca a mulher que sofreu a violência e, também é oportuno ao agressor, pois ele continuará a reproduzir essa violência contra outras mulheres. ${ }^{1}$

A partir das entrevistas realizadas com as jornalistas mulheres em atuação no Rio Grande do Sul, buscamos entender a força que têm seus enunciados e o que elas querem dizer com o que estão dizendo. Procuramos compreender como essas mulheres reagem a esse sofrimento.

\subsection{Além da teoria: relatos de violência contra mulheres jornalistas}

As entrevistas foram realizadas com 13 jornalistas mulheres do Rio Grande do Sul, com idade entre 23 e 48 anos, as quais relatam suas experiências profissionais e como gênero gera implicações no exercício da profisssão. Os relatos colhidos correspondem às violências sofridas pelas entrevistadas, situações que presenciaram ou ouviram sobre colegas mulheres de profissão. As entrevistadas são de diferentes regiões do Estado, mas atuam no Rio Grande do Sul e os encontros com as mesmas se deram de forma presencial. Na ocasião foi explicado para elas o intuito da pesquisa, todas assinaram um termo de livre esclarecimento tratado como um documento científico que está sob poder dos pesquisadores desse trabalho.

\footnotetext{
${ }^{1}$ Já que não existiu um confronto perante seu comportamento. No entanto, compreendemos que confrontar o agressor não é uma decisão fácil, há diversos motivos que fazem com que a vítima opte pelo silêncio: o medo de ser demitida, receio de ser culpabilizada ou desacreditada, não querer reviver o trauma, além das relações de poder que existem dentro desses espaços, onde, apesar das redações serem compostas em sua maioria por jornalistas mulheres, se tem uma predominância de homens em cargos de chefia.
} 
Metodologicamente optamos por não escrever na íntegra as entrevistas realizadas e, dada a consciência dos pesquisadores no tratamento da amostra, a alternativa que pareceu mais interessante foi a de recortar das entrevistas os dizeres que interessavam argumentativa e analiticamente.

A pesquisa buscou antes de tudo reconhecer em cada dizer quais enunciados e que marcas discursivas essas mulheres traziam ao falar de seus sentimentos sobre violência. Essa prática de expressão e narratividade coloca-se como um instrumento de comunicação não violenta. Conforme Barter (2012), a violência está em não poder expressar o sentimento ou a dor sofrida de uma maneira dialógica.

$\mathrm{Na}$ pesquisa, constatamos oito situações de violência sofridas pelas mulheres jornalistas entrevistadas, são elas: assédios diários que acontecem em forma de "elogios", recompensas e sanções, onde propomos refletir nosso material empírico com base na teoria de Warren Breed (1993) sobre as recompensas e sanções no jornalismo, nesse sentido buscamos entender a partir de Breed os constrangimentos sofridos por mulheres jornalistas no ambiente de trabalho. Outra situação diz respeito ao mansplaning e manterrupting no jornalismo, dois termos recentes, o primeiro é quando um homem explica para uma mulher algo que ela já sabe e o segundo quando um homem interrompe uma mulher repetidamente durante sua fala. Apuramos também os assédios cometidos por fontes jornalísticas e público, assim como os assédios cometidos no meio online, em sites como Youtube e portais de Chats. Nesse artigo, devido ao limite de espaço não será possível abordar todas as situações, devido a isso aprofundaremos nos próximos tópicos apenas três constrangimentos identificados na pesquisa, são eles: bropropriating, um termo recente, que diz respeito à quando um homem rouba a ideia de uma mulher sem dar os devidos créditos; penalidades sofridas por mulheres jornalistas que são mães e, por último, assédios sofridos por mulheres jornalistas negras.

\section{2 "Essa ideia é minha": bropropriating no jornalismo}

O termo "Bropropriating" teve sua primeira aparição através de um artigo intitulado “Como não ser 'manterrupted' (interrompida por homens) em reuniões” (How Not to Be 'Manterrupted' in meetings) publicado em 2015 na revista Time pela jornalista Jessica Bennet. No artigo, a autora explica que não é responsável pela autoria do termo, mas que foi uma expressão que teve seu surgimento em conversa entre amigos.

A expressão é um neologismo em língua inglesa formado pela junção do prefixo "Bro", que nesse sentido tem o significado de "Brother", que em português representaria a 
gíria "Cara", e a palavra inglesa "propriating", que significa apropriação. O termo se refere a situações em que homens tomam para si crédito de ideias expressadas por mulheres, na maioria das vezes isso ocorre em situações profissionais. A expressão também possui uma versão reduzida e é mais conhecida por ela: bropriating.

Um caso bastante repercutido em veículos midiáticos nos Estados Unidos sobre bropropriating aconteceu em 2016, quando um grupo de mulheres que trabalhava na equipe de assessores do ex-presidente dos Estados Unidos, Barack Obama, criou uma estratégia para lidar com as interrupções constantes e apropriações de suas ideias por colegas homens, que eram maioria. A técnica, chamada "amplification", consistia em uma mulher repetir e dar crédito a ideias propostas por outras mulheres no momento em que aconteciam, com isso os homens acabavam reconhecendo o que estava sendo proposto e não tomavam para si a autoria.

A entrevistada $11^{2}$ trabalha com jornalismo há quatro anos e atualmente atua em uma agência de comunicação. Uma dificuldade encontrada em seu último trabalho foi de não ser escutada toda vez que sugeria uma ideia, no entanto, sempre que um colega de trabalho repetia as sugestões oferecidas por ela era escutado.

Eu percebi que se eu quisesse que minha ideia fosse levada a sério no meu último trabalho, eu tinha que passar minha ideia para ele [colega] e ele levava. Então, era a única maneira de eu exercer meu trabalho, porque se eu colocasse a ideia na mesa, eu não era escutada. Ele levava os créditos, mas era a única maneira de eu me movimentar (ENTREVISTA 11, 2018).

Se posicionar no ambiente de trabalho é uma dificuldade encontrada pelas jornalistas em início de carreira. A entrevistada 9 trabalha como jornalista há oito anos no segmento impresso e online de um dos grandes veículos midiáticos do Rio Grande do Sul. Para ela, a dificuldade de se impor em reuniões e conversas com colegas de trabalho se dá porque a redação jornalística não é um ambiente de acolhimento, o que faz com que as novas profissionais se sintam acuadas.

É mais difícil tu se posicionar quando é nova. Conforme a gente vai amadurecendo na vida e como profissional, a gente consegue exigir um respeito maior. Então, quando algum colega vem com algum papo, eu já corto na hora, porque tu consegues te colocar de uma maneira mais firme, tu

\footnotetext{
${ }^{2}$ Para manter a integridade moral e física das entrevistadas não utilizaremos seus nomes. Optamos por não chamar as entrevistadas de "sujeito" e nem dar a elas nomes fictícios. Trabalhamos com uma identidade genérica neutra numérica, nesse sentido temos a entrevistada 1 até a entrevistada 13.
} 
aprendes a te posicionar mais claramente. Já sofri muitas interrupções, mas hoje consigo me posicionar (ENTREVISTA 9, 2018).

Segundo Mena (2017), o bropropriating acontece precedido de uma interrupção da fala da mulher por um homem, logo em seguida, o mesmo repete a ideia como se fosse sua. É comum que use artifícios como postura de propriedade, variações no tom de voz, na escolha de palavras etc. Outra forma usual de Bropriating é o silêncio após uma mulher propor algo (em uma reunião, por exemplo) e, pouco tempo depois, o mesmo ser proposto por um homem e, então, ser recebido como uma ótima ideia (MENA, 2017).

Pensar sobre lugares de enunciação (ZOPPI FONTANA, 2002) é importante para refletir a prática do broproprating. Os lugares de enunciação dizem respeito a configuração de um modo de dizer, ou seja, o espaço de circulação, a legitimidade, a organização enunciativa e são "diretamente afetados pelos processos históricos de silenciamento" (ZOPPI FONTANA, 2017, p.66).

(...) noção de lugar de enunciação poderia resumir-se como uma reflexão sobre a divisão social do direito de enunciar e a eficácia dessa divisão e da linguagem em termos da produção de efeitos de legitimidade, verdade, credibilidade, autoria, circulação, identificação, na sociedade (ZOPPI FONTANA, 2002, p. 16).

Orlandi (2010, p.75) afirma que o sujeito possui um lugar de significação historicamente constituído, ou seja, "uma posição". A autora diz que essas posições correspondem, mas não equivalem simplesmente à presença física dos organismos humanos ou lugares da estrutura social. "São lugares 'representados' no discurso, isto é, estes lugares estão presentes, mas transformados nos processos discursivos". Através das falas das entrevistadas, constatamos que esse lugar enunciativo das mulheres em seus ambientes de trabalho é restrito. As mesmas não são propriamente ouvidas e quando são, diversas vezes, tem os créditos de suas ideias atribuídas à outra pessoa. Desse modo, o que está relacionado com o enunciado não é o sujeito em si, mas suas posições ou seus lugares na formação social.

Esse lugar enunciativo das mulheres em seus ambientes de trabalho é restrito. As mesmas não são propriamente ouvidas e quando são, diversas vezes, tem os créditos de suas ideias atribuídas à outra pessoa. Isso se dá, porque a força do discurso masculino se sobrepõe sobre o discurso feminino. 


\subsection{Penalidade por ser mãe: sanções a jornalistas grávidas}

Um estudo realizado por Correll e Benard (2007) com o intuito de identificar a existência de penalidades às mães no mercado de trabalho constatou que as candidatas a vagas de emprego que possuem filhos têm $44 \%$ a menos de chance de serem contratadas do que as mulheres sem filhos, mesmo possuindo a mesma qualificação. Segundo os autores, a penalidade da maternidade, no que diz respeito aos salários e avaliações de desempenho no trabalho, ocorrem devido a um entendimento cultural do papel da maternidade onde há uma tensão no que seria entendido como um "trabalhador ideal", e mães não se encaixam nesse imaginário social. Com isso, mesmo que inconscientemente, os chefes e contratantes esperam que as mulheres com filhos sejam menos competentes e menos comprometidas com seus empregos.

A entrevistada 13 trabalha com jornalismo há 12 anos e atualmente é repórter multimídia em um jornal do Rio Grande do Sul. Ela relata que quando ficou grávida sofria constantes ameaças sutis de seu chefe e se sentia violentada com os comentários que ouvia.

Eu trabalhava em uma empresa jornalística e várias vezes eu precisei faltar para consulta de pré-natal, claro que eu remarcava, mas isso era uma violência né, porque eu tinha um compromisso com minha saúde e com a saúde do meu filho e eu não podia ir porque eu era ameaçada, não diretamente, mas muitas ameaças veladas. Por exemplo, ele dizia 'Quando tu voltar não sei se tu vais continuar, porque mulher que tem filho fica com a cabeça só no filho, não consegue mais tocar a carreira' (ENTREVISTA 13, 2018).

O estudo de Correll e Benard (2007), aponta que no mercado de trabalho o efeito paternidade acontece de forma inversa. Ser um bom pai não é entendido como culturalmente incompatível com ser um trabalhador ideal. Nesse contexto, "ser pai" e ser um "trabalhador ideal" faz parte do "pacote" desejado pelas empresas.

A entrevistada 13 relata que a percepção de seu chefe sobre como seria seu comprometimento após a volta da licença maternidade estava equivocada, pois seus resultados profissionais foram positivos.

Meu chefe na época estava errado, porque quando eu voltei, eu cresci na empresa. Ele mesmo me falou depois que achava que eu não ia durar, que tinha contratado outra pessoa para o meu lugar e teve que deslocar essa pessoa, porque eu tinha conquistado meu lugar e ele disse que eu tinha voltado ainda mais entusiasmada. Até me senti mal na época, hoje vejo que não tinha que ter me sentido mal, eu não entendi como um elogio, entendi como uma agressão, por que eu tinha um filho eu não podia ser boa? (ENTREVISTA 13, 2018) 
Uma pesquisa intitulada "Mulheres no mercado de trabalho" (Women in the Workplace) de 2015 aponta que mulheres que são mães possuem maior produtividade e são $15 \%$ mais interessadas em cargos mais altos do que mulheres sem filhos. Devido a isso, as mesmas se esforçam muito mais em seu trabalho para obterem melhores resultados, como é o caso da entrevistada 13.

\subsection{Assédios e constrangimentos sofridos por mulheres jornalistas negras}

Um levantamento realizado pelo coletivo de mídia Vaidapé em 2016 (SANTANA e SALLES, 2016) identificou o número de apresentadores negros no Brasil nas principais emissoras de televisão da rede aberta do país: Cultura, SBT, Rede Globo, Rede Record, Rede TV, Gazeta e Bandeirantes. Em um primeiro momento, o coletivo entrou em contato com as emissoras a fim de descobrir quantos apresentadores negros eram contratados, porém, os números fornecidos não eram claros. A partir disso, o coletivo organizou um estudo com objetivo de dimensionar a divisão racial entre os apresentadores de televisão brasileiros.

$\mathrm{Na}$ pesquisa, foram checados 204 programas de televisão das sete emissoras selecionadas, entre o segundo semestre de 2016 e o primeiro de 2017 . O resultado constatou a existência de 272 apresentadores compondo as grades de programação. As primeiras respostas mostraram que apenas $3,7 \%$ dos apresentadores são negros, dos 272 apresentadores encontrados somente 10 são negros.

Os dados obtidos na pesquisa vão de desencontro com a proporção de pessoas negras que compõem a população brasileira. Segundo a Pesquisa Nacional por Amostra de Domicílios (PNAD) de 2015, realizada pelo Instituto Brasileiro de Geografia e Estatística (IBGE), no que se refere à cor ou raça, $45,1 \%$ da população brasileira se considera parda e $8,9 \%$ se considera negra.

Sodré (1999) denomina "síndrome de vampiro" o fato de os negros não conseguirem enxergar sua imagem no espelho da mídia. Segundo o autor, através da análise de propagandas, produções cinematográficas e, principalmente, na televisão é possível comprovar essa realidade. Para ele, a mídia exerce um papel de relevância na criação de imagens e estereótipos.

Ao realizar essa pesquisa, procuramos as entrevistadas aleatoriamente através das redes sociais. Ao pesquisar através do Linkedin, Facebook e Instagram, poucas vezes apareciam jornalistas mulheres negras. Essa questão foi claramente percebida quando recebemos o retorno das 13 entrevistadas que se disponibilizaram a ajudar no estudo, apenas 
duas dessas eram mulheres negras. A pesquisa realizada em 2012 pela Universidade Federal de Santa Catarina em parceria com a Federação Nacional dos Jornalistas (FENAJ) revela que apenas 5\% dos jornalistas brasileiros são negros e negras, $18 \%$ são pardos e pardas, enquanto $72 \%$ são brancos e brancas.

Nesse contexto, é possível perceber que o percentual de negros jornalistas é inferior à metade de pessoas pretas e pardas brasileiras. A entrevistada 11 trabalha com jornalismo há quatro anos e atualmente exerce a função de mídias sociais na empresa em que trabalha. Durante a entrevista ela relata que possuía um desejo de trabalhar com televisão, mas que precisou desistir porque sentia que não correspondia aos padrões desejados pelas empresas, já que é negra. Ela relata que quando trabalhou na área de televisão existia situações pontuais que a incomodavam relacionadas a ofensas sutis sobre seu cabelo.

Eu estava fazendo uma passagem e minha diretora falou assim: "Quando tu for fazer boletim, pode prender teu cabelo, por favor? Porque ele chama muita atenção na reportagem". É claro que no outro dia fui com cabelo maior ainda, porque achei um desaforo. Teve uma outra situação que foi com o chroma key, pediram para eu prender o cabelo porque "É difícil de chromar" e aí eu falei "É difícil de chromar porque vocês não são profissionais o suficiente pra chromar cabelo crespo, então vocês vão aprender comigo, é uma oportunidade para mim e para vocês". A partir disso, eu comecei a bater de frente e me impor (ENTREVISTA 11, 2018).

Ela conta que quando trabalhou com televisão era considerada uma profissional com boa desenvoltura, mas que não podia apresentar um programa que iria para televisão nacional porque: /eu não tinha uma boa aparência, não era esteticamente aceitável, segundo eles/, os apelidos que remetem sua cor também são constantes no meio de trabalho: /Quando tu entras tem os apelidos como Globeleza, moreninha, mulatinha/.

Nesse contexto, constatamos que os constrangimentos sofridos por mulheres jornalistas negras possuem características diferentes e vão além do que as mulheres jornalistas brancas relatam. A interseccionalidade (CRENSHAW, 1989) traz outras formas de violência, problemas referentes a sexismo e racismo, se sobrepõem, criando múltiplos níveis de violência e discriminação que uma mulher negra pode sofrer em seu ambiente de trabalho. Esses sistemas discriminatórios de que fala Crenshaw (op.cit), vão além de raça e gênero, dizem respeito também a classe, sexualidade, biótipo, etc., esses sistemas se sobrepõem ou se entrecruzam, criando intersecções complexas que atingem, principalmente, mulheres negras.

Essas outras formas de agressão que essas mulheres negras podem sofrer se apresentam através de desvalorização no ambiente de trabalho, julgamento de seus traços 
étnicos, apelidos com conotação racial depreciativa e imposições de mudança de identidade. Tudo isso, acaba afetando sua atuação no ambiente de trabalho.

\title{
2.5 O silêncio perante as violências sofridas
}

Segundo Rosenberg (2006), a comunicação não-violenta (CNV) tem como intuito substituir os velhos padrões de defesa e ataque, através de um novo enfoque. Nesse sentido, as reações violentas são minimizadas. Para a $\mathrm{CNV}$, os conflitos violentos ou negativos podem ser resolvidos e compreendidos através do diálogo.

No nosso estudo, entendemos que o diálogo não se dá apenas entre a vítima e o agressor, mas também entre a vítima e a chefia da empresa, buscando a resolução do problema, pois entendemos que para vítima nem sempre é fácil e simples enfrentar o agressor.

Ao final de cada entrevista, perguntamos às entrevistadas se as situações de assédio e constrangimentos relatadas haviam sido discutidas com o agressor ou levadas até os órgãos competentes da empresa. Das treze, nove delas afirmaram que em algum momento da carreira se silenciaram e não enfrentaram o agressor ou levaram o caso aos órgãos competentes.

No entanto, todas acreditam que esse silêncio colabora para que esse problema permaneça, já que sem o enfrentamento o agressor não reflete sobre suas ações e a empresa não toma conhecimento do que acontece, permitindo que a prática continue.

A entrevistada 1 relata que na antiga empresa no qual trabalhava duas meninas já foram assediadas por uma mesma pessoa. Sobre isso, ela diz:

\begin{abstract}
A partir do momento que há uma segunda e a primeira já não falou nada, de certa forma, pode parecer cruel o que eu estou dizendo, porque eu entendo todo o contexto, mas toda mulher que é abusada de alguma forma e não denuncia, ela contribui para a próxima. Não é garantia de que não vai acontecer se ela contar, mas é certificado que vai acontecer com outra. Então é muito esse discurso, ela já é a segunda porque a primeira não falou, se ela não falou vai ter a terceira. Ela não conta por medo de ser demitida, e o mais incrível é fomos[eu e marido] falar com a primeira para ver se elas juntas tem força, e ela alega que ela não conta porque como ela tem fama de festeira a empresa vai dizer que é mentira (ENTREVISTA 1, 2018).
\end{abstract}

A entrevistada 2 é uma das entrevistadas que denunciou à polícia o caso de assédio sofrido no ambiente de trabalho. O agressor era o cliente da vítima, ela relata que o mesmo trabalha como coach e em uma reunião de trabalho usou de técnicas da sua profissão para assediá-la, segundo ela o que impediu que uma agressão física acontecesse foi a calma que ela manteve para sair da situação o mais rápido possível, ela relata que por não ter se calado 
diante da situação ouviu muitos comentários criticando seu posicionamento: /Quando tu denuncia, como foi meu caso que não teve assédio físico consumado, as pessoas dizem "ah mas nem tudo isso", mas não foi por que? Porque eu conduzi a situação muito bem/.

Acho que a violência é um espiral, e para tudo existem formas. O silêncio é uma forma de manter ela ali, rolando, rolando e rolando. Enquanto não vier uma coisa e parar ela, que eu acredito que seja a quebra do silêncio, com um discurso não agressivo, pois eu acredito que violência gera violência, quando o silêncio corta aquela espiral ele diminui aquela onda de violência (ENTREVISTA 2, 2018).

Os motivos relatados pelas entrevistadas para não falarem sobre o ocorrido são relacionados ao medo de perder o emprego, receio de denunciar e não ser recolocada no mercado de trabalho, de reviver o trauma e de ser desacreditada. Nesse contexto, a omissão da própria vítima se torna um obstáculo, pois o constrangimento vivido não é enfrentado e dá abertura para novos acontecimentos direcionados a outras mulheres, o silêncio se torna uma forma de comunicação violenta.

\section{CONSIDERAÇÕES}

As escolhas para uma pesquisa acadêmica nunca possuem apenas um porquê. São inúmeras inquietações que nos levam a escolher determinado objeto para trabalharmos seguindo certos caminhos. A escolha por pesquisar jornalismo e gênero se deu devido aos tensionamentos existentes que nos deixavam indagações sobre a temática dessa pesquisa. Essa natureza transdisciplinar despertou novos conhecimentos para nossa investigação, foi através da interligação dos estudos de gênero e dos estudos sobre jornalismo que foi possível refletir sobre as problemáticas contemporâneas relacionadas as mulheres jornalistas.

As instituições sociais como a família, a escola, a igreja, a sociedade e a mídia colaboram na construção do que se espera e do que se pensa sobre as mulheres. É inegável os avanços que elas conquistaram ao decorrer da história. Principalmente, as mulheres jornalistas que alcançaram credibilidade dentro do mercado de trabalho adentrando redações e se arriscando em diferentes editorias. Hoje, podemos dizer que não existe um jornalismo feito só por homem.

No entanto, um mercado que a todo momento se expande como o jornalismo ainda gera constrangimentos à mulher jornalista. $\mathrm{O}$ medo das sanções não se limita apenas ao que o autor Warren Breed estabelece, já que não é apenas a organização e a política editorial da empresa que pode causar algum constrangimento, para as mulheres vai muito além. Observamos, que mesmo os constrangimentos mais sutis geram efeitos profundos na vida 
dessas mulheres que se sentem ridicularizadas, desvalorizadas e desmotivadas em seus ambientes de trabalho.

As formas de violência contra mulheres jornalistas foram mapeadas ao decorrer dessa pesquisa, e os constrangimentos vão além das piadas, brincadeiras, deboches e comentários sexistas (que constatamos serem muito comuns no ambiente do jornalismo). Para além disso, percebemos que as violências se modificam e se intensificam com diferentes mulheres. As mulheres negras, por exemplo, vivenciam a interseccionalidade (CRENSHAW, 1989) de gênero e raça, sofrendo outros tipos de constrangimentos.

A omissão perante as violências sofridas se dá devido ao medo da demissão, de não serem recolocadas no mercado de trabalho após uma denúncia e de serem desacreditadas pela chefia e colegas de trabalho. Com esses medos, as vítimas optam pelo silêncio diante das condutas abusivas e desrespeitosas do agressor, pois acreditam que com o tempo as situações constrangedoras se acalmam.

Ao quebrarem esse silêncio ${ }^{3}$ as jornalistas provocam mudanças imensas, não apenas em suas vidas, mas nas vidas das colegas de trabalho. São essas atitudes de não se calar, questionar, refletir e exigir respeito que provocam mudanças sociais, políticas e legais que são essenciais à evolução, não apenas das mulheres, mas do ser humano.

Essa pesquisa possui relevância no contexto atual, pois as temáticas trabalhadas e que estão relacionadas a gênero, assédio e constrangimento sofridos por mulheres jornalistas são pautas atuais do senso comum e discutidas constantemente em redes sociais. Nesse sentido, a academia precisa abordar estes fenômenos cientificamente.

Dentro da pesquisa, a configuração metodológica foi parte essencial durante a investigação e construção da mesma. Foi através dos relatos colhidos nas entrevistas que fortalecemos nossas concepções teóricas acerca do tema. Os estudos de discurso em nosso trabalho não fundamentaram apenas a compreensão dos processos e fenômenos discursivos, também foram estratégias metodológicas em nossa investigação. Também, destacamos que

\footnotetext{
${ }^{3}$ Evidentemente que se pode relativizar o silêncio. Pode parecer à primeira vista que o argumento seja de que as mulheres optem por ele, mas sabemos que não é bem por aí. A decisão de não reagir e de ser violentada por este silenciamento tem a ver muito mais com outras questões que com seu papel de dupla vítima. Refém da violência e anulada em sua estima e poder, a mulher se encontra vulnerável a reações, pelo que ela sofre sem responsabilidade. Se é verdade que cabe a ela reagir e não silenciar à violência porque isso acaba por estimular a repetição da agressão, nas formas de uma comunicação não violenta, não é menos verdade que não se trata apenas de querer ou não. Há muitos elementos em jogo e por isso apoios sociais e uma série de medidas protetivas são mais fundamentais que apenas sua disposição para quebrar o ciclo da violência que sofrem.
} 
entender o fenômeno através da Comunicação Não-Violenta trouxe novas contribuições nos estudos de gênero aliado ao jornalismo.

\section{REFERÊNCIAS}

ASSIS, Carolina. Pesquisa Inédita da Gênero e Número e da Abraji traz retrato do machismo no jornalismo brasileiro. Gênero e Número, 2017. Disponível em: <

http://www.generonumero.media/pesquisa-da-genero-e-numero-e-da-abraji-traz-retrato-do-machismono-jornalismo-brasileiro/ > Acesso em 22 mai. de 2018.

BARTER, Dominic. Comunicação não violenta: uma base ética para práticas restaurativas. In: Justiça para o século XXI: instituindo Práticas Restaurativas. Material de apoio - Curso de Formação em Práticas Restaurativas. Mimeo. Texto integrante da publicação Justiça Restaurativa, da Secretaria da Reforma do Judiciário, Ministério da Justiça e PNDU, s/d, 2012. Disponível em: < www.mj.gov.br $>$ Acesso em 06 mai. de 2018.

BOURDIEU, Pierre. A dominação masculina. Rio de Janeiro: Bertrand Brasil, 2011.

BREED, Warren. Controle Social na Redação. Uma análise Funcional. In TRAQUINA, Nelson (Org). Jornalismo: questões, teorias e estórias. Lisboa: Veja, 1993, pp.152-166.

BUTLER, Judith. Problemas de Gênero: Feminismo e subversão da identidade. Rio de Janeiro: Civilização Brasileira, 2003.

CORRELL, Shelley; BENARD, Stephen. Getting a job: Is there a motherhood penalty? American Journal of Sociology, Vol. 112, n.5, p. 1297-1339, 2007.

CRENSHAW, Kimberlé. Demarginalizing the intersection of race and sex: a black feminist critique of discrimination doctrine, feminist theory and antiracist politics. University of Chicago Legal Forum, pp. 139-167, 1989.

FRIEDMAN, Betty. Mística feminina. Petrópolis: Vozes, 1971.

GAUNTLETT, David. Media, gender and identity: an introduction. New York: Routledge, 2002.

HALL, Stuart. Quem precisa da identidade? In: SILVA, Tomaz Tadeu da. (org.) Identidade e Diferença. Petrópolis: Vozes, 2000. p.109.

MCKINSEY \& COMPANY. Women in the workplace. 2015. Disponível em: < https://www.nmhc.org/uploadedFiles/Articles/External_Resources/McKinseyLeanIn\%20Women_in_the_Workplace_2015.pdf > Acesso em: 03 out. de 2018.

MENA, Isabela. Verbete Draft Feminismo nos negócios: o que é bropriating. Draft, 2017.

Disponível em: < https://projetodraft.com/verbete-draft-feminismo-nos-negocios-o-que-e-bropriating/ $>$ Acesso em 22 mai. de 2018.

MICHEL, Maria Helena. Metodologia e pesquisa científica em ciências sociais. São Paulo: Atlas, 2005.

MICK, Jacques; LIMA, Samuel (coord.). Perfil do jornalista brasileiro: características demográficas, políticas e do trabalho jornalístico em 2012. Florianópolis: Editora Insultar, 2013.

ORLANDI, Eni. Nota ao Leitor. In: PÊCHEUX, Michel. O discurso: estrutura ou acontecimento. [trad.] Eni Puccinelli Orlandi. 4ed. Campinas: Pontes, 2006. 
ORLANDI, Eni. Análise de Discurso: Princípios e Procedimentos. São Paulo: Pontes Editores, 2010.

PÊCHEUX, Michel. Análise Automática do Discurso. IN GADET, F. HAK, T. (Org.). Por Uma Análise Automática do Discurso: Uma Introdução à Obra de Michel Pêcheux. $3^{\mathrm{a}}$ Ed. Campinas, SP: Editora da UNICAMP, 1997, p. 74.

PESQUISA NACIONAL POR AMOSTRA DE DOMICILIOS. Síntese de indicadores 2015. IBGE, Coordenação de Trabalho e Rendimento. - Rio de Janeiro: IBGE, 2016.

ROCHA, Paula Melani. As mulheres jornalistas no Estado de São Paulo: O processo de profissionalização e feminização da carreira. 2004. Tese de doutorado (Programa Pós-graduação em Ciências Sociais) - Centro de Educação e Ciências Humanas, Universidade Federal de São Carlos, São Carlos.

ROSENBERG, Marshall. Comunicação não-violenta: Técnicas para aprimorar relacionamentos pessoais e profissionais. São Paulo: Ágora, 2006.

SANTANA, Henrique; SALLES, Iuri. Por que os negros não apresentam programas de TV. Vaidapé, 2017. Disponível em: < http://vaidape.com.br/2017/06/pesquisa-apresentadores-negros-natelevisao/ > Acesso em 03 out. de 2018.

SCOTT, Joan. Gender: A Useful Category of Historical Analysis. In: Gender and the Politics of History. Nova Iorque, Columbia University Press, 1988.

SODRÉ, Muniz. Claros e Escuros: identidade, povo e mídia no Brasil. Petrópolis: Vozes, 1999.

STOCKER, Pâmela; DALMASO, Silvana. A cultura do estupro entra na pauta: a disputa de sentidos entre jornalismo e leitores do Diário Gaúcho. In: Brazilian Journalism Research, 2018. Disponível em: < https://bjr.sbpjor.org.br/bjr/article/download/1025/pdf_1> Acesso em: 09 mai. de 2018.

STUMPF, Ida Regina C. Pesquisa Bibliográfica. In: DUARTE, Jorge; BARROS, Antonio. Métodos e Técnicas de Pesquisa em Comunicação. São Paulo: Atlas, 2005.

TIVE de ser 'sargentona' para ganhar respeito, lembra jornalista pioneira no Brasil. BBC BRASIL, 2017. Disponível em: < https://www.bbc.com/portuguese/brasil-40101297 > Acesso em: 04 out. de 2018.

VEIGA, Marcia. Gênero: um ingrediente distintivo nas rotinas produtivas do jornalismo. Estudos em Jornalismo e Mídia, v. 9, p. 490-505, 2012.

WOLF, Naomi. O mito da beleza: como as imagens de beleza são usadas contra as mulheres. Rio de Janeiro: Rocco, 1992.

ZOPPI FONTANA, Monica. 'Lugar de fala': enunciação, subjetivação, resistência. CONEXÃO LETRAS, v. 12, p. 63-71, 2017.

ZOPPI FONTANA, Monica. Lugares de enunciação e discurso. LEITURA-Análise do 71 Volume 12, no 18 | 2017 Discurso. Revista do Programa de Pós-graduação em Letras e Linguística. Maceió, v. 23, jan/jun 1999 [2002], p.15-24. 


\section{Louise Ariane da Campo}

Mestranda pelo Programa de Pós-graduação em Letras na linha de pesquisa "Texto, Discurso e Relações Sociais" pela Universidade Federal de Pelotas. Jornalista formada pela Universidade Federal do Pampa.

Geder Luis Parzianello

Professor Associado da Universidade Federal do Pampa, doutor em comunicação com pós-doutorado em Estudos de Mídia pela Universität Paderborn, Alemanha. Bolsa Capes (2012-2013).$$
\text { @ } \odot \Theta \odot
$$

Esta obra está licenciada com uma Licença Creative Commons Atribuição-NãoComercial-CompartilhaIgual 4.0 Internacional 